\title{
Partial Splenic Artery Embolization for Idiopathic Warm Autoimmune Hemolytic Anemia Refractory to Medical Therapy
}

\begin{abstract}
Purpose: While Partial Splenic Artery Embolization (PSAE) is a useful procedure that has been performed for a variety of indications including trauma and hypersplenism, it has only been rarely described as a treatment for Idiopathic Warm Autoimmune Hemolytic Anemia. Previous reports in the literature are limited to case reports in situations that include the patient being a poor surgical candidate, the inability to transfuse blood during surgery because of autoantibodies, and a patient's refusal of blood products on religious grounds. Materials and Methods: A case report describing the case of a 27-year-old male diagnosed with idiopathic warm Autoimmune Hemolytic Anemia treated successfully with partial splenic artery embolization (PSAE) as a bridging therapy to definitive surgical splenectomy. Results: The patient's pre-procedure hemoglobin was $2.1 \mathrm{~g} / \mathrm{dl}$. The first hemoglobin post-procedure was $4.5 \mathrm{~g} / \mathrm{dl}$. After embolization, the patient remained in the inpatient setting for eight days for close observation. During the inpatient hospitalization the patient's hemoglobin continued to trend upwards until it stabilized around $6 \mathrm{~g} / \mathrm{dl}$. Inpatient laboratory workup also showed increasing haptoglobin, and decreasing LDH. After discharge, the patient developed persistent pain two months post-procedure. An elective splenectomy was scheduled three months after the embolization procedure to address the persistent pain. Six months' post embolization procedure and three months postoperatively, the patient is doing well clinically with a hemoglobin of $14 \mathrm{~g} / \mathrm{dl}$. Conclusion: In conclusion, this case demonstrates the utility of a Partial Splenic Artery Embolization (PSAE) as an acute life-saving intervention for poor surgical candidates with idiopathic warm Autoimmune Hemolytic Anemia (AIHA) refractory to medical therapy.
\end{abstract}

Keywords: Splenic artery embolization; autoimmune hemolytic anemica; embolization; anemia

\section{Introduction}

While partial splenic artery embolization (PSAE) is a useful procedure that has been performed for a variety of indications including trauma and hypersplenism, it has only been rarely described as a treatment for idiopathic warm autoimmune hemolytic anemia (AIHA). Previous reports in the literature are limited to case reports in situations that include the patient being a poor surgical candidate, the inability to transfuse blood during surgery because of autoantibodies, and a patient's refusal of blood products on religious grounds. Warm AIHA is caused by increased red blood cell destruction triggered by antibodies reacting against red blood cell surface antigens. It is the most common form of AIHA. First-line therapy for warm AIHA consists of corticosteroids. For cases that

This is an open access journal, and articles are distributed under the terms of the Creative Commons Attribution-NonCommercial-ShareAlike 4.0 License, which allows others to remix, tweak, and build upon the work non-commercially, as long as appropriate credit is given and the new creations are licensed under the identical terms.

For reprints contact: WKHLRPMedknow_reprints@wolterskluwer.com are refractory to steroid management, the current management for second-line therapy is splenectomy, rituximab, and thereafter alternative immunosuppressive medications.

\section{Case Report}

This is a 27-year-old male diagnosed with idiopathic warm AIHA treated successfully with PSAE as a bridging therapy to definitive surgical splenectomy. The patient presented with 2 days history of nausea, vomiting, and epigastric pain. His examination was significant for scleral icterus and sublingual jaundice. Laboratory workup showed low hemoglobin of $5.5 \mathrm{~g} / \mathrm{dl}$ and hematocrit of $15.7 \%$. White blood cell count was $6 / \mu \mathrm{L}$, and platelet count was $181 / \mu \mathrm{L}$. Total bilirubin was elevated (10), haptoglobin was low $(<8 \mathrm{~g} / \mathrm{dl})$, and lactate dehydrogenase (LDH) was elevated (969U/L). His direct Coombs test was positive. No splenomegaly noted on the initial computed tomography (CT) scan. The patient was

\footnotetext{
How to cite this article: Hadied MO, Kherallah RY, Salman M, Eteer K, Schwartz S. Partial splenic artery embolization for idiopathic warm autoimmune hemolytic anemia refractory to medical therapy. Arab J Intervent Radiol 2020;4:130-3.
}

\section{Mohamad Omar Hadied, Riyad Yazan Kherallah', Mariam Salman', Khalid Eteer ${ }^{3}$, Scott Schwartz}

Department of Radiology, Henry Ford Health System, Detroit, MI, ${ }^{I}$ Department of Internal Medicine, Baylor College of Medicine Medical Center, Houston, TX, ${ }^{2}$ University of Michigan Medical School, Ann Arbor, MI, ${ }^{3}$ School of Medicine, Wayne State University, Detroit, MI, USA

\section{Received: 25-11-2019 \\ Revised: 31-12-2020 \\ Accepted: $22-01-2020$ \\ Online Published: 25-04-2020 \\ Address for correspondence: Dr. Mohamad Omar Hadied, Department of Radiology, Henry Ford Health System, Detroit. MI, USA. \\ E-mail:mohamadh@rad.hfh.edu}

Access this article online

Website: www.arabjir.com

DOI: 10.4103/AJIR.AJIR_33_19

Quick Response Code:
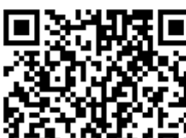

arghts 
diagnosed with idiopathic warm AIHA and started on intravenous methylprednisolone $1 \mathrm{~g} /$ day.

Before presentation at our institution, the patient was managed at an outside hospital where he received corticosteroids, an immunosuppressant, and twelve transfusions. The patient was transferred to our institution for escalation of care after developing autoantibodies that precluded future administration of transfusions.

On arrival, the patient's hemoglobin was $4.5 \mathrm{~g} / \mathrm{dl}$. Rituximab, vincristine, and cytoxan were administered. Methylprednisolone was restarted and continued throughout the hospital course. On hospital day 3, intravenous immunoglobulins (Igs) were administered with poor tolerance. Despite these interventions, the patient's hemoglobin continued to trend downward, reaching a nadir of $2.3 \mathrm{~g} / \mathrm{dl}$. A repeat $\mathrm{CT}$ of the abdomen showed an enlarged spleen with a span of $16.5 \mathrm{~cm}$ in its maximum dimension [Figure 1].

The patient's hemodynamic instability made him a poor surgical candidate. As such, the decision was made to

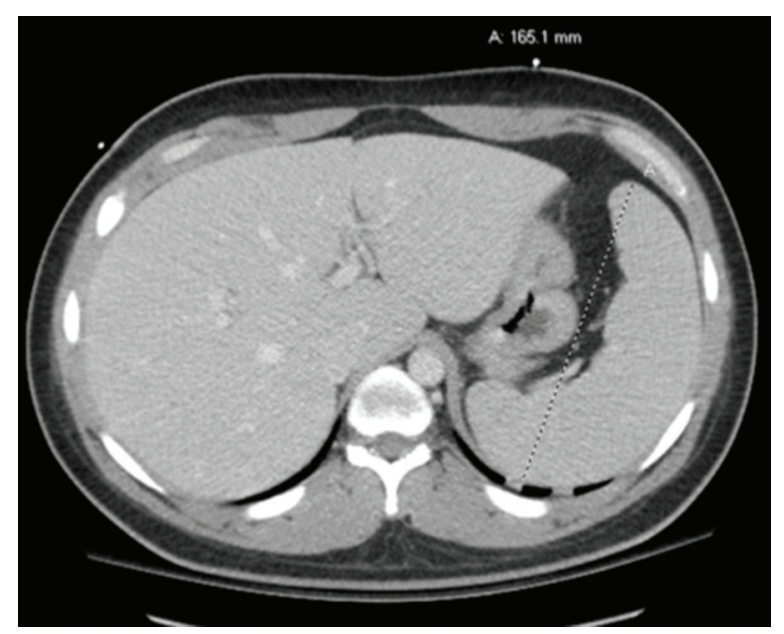

Figure 1: Preprocedure computed tomography of the abdomen showing splenomegaly

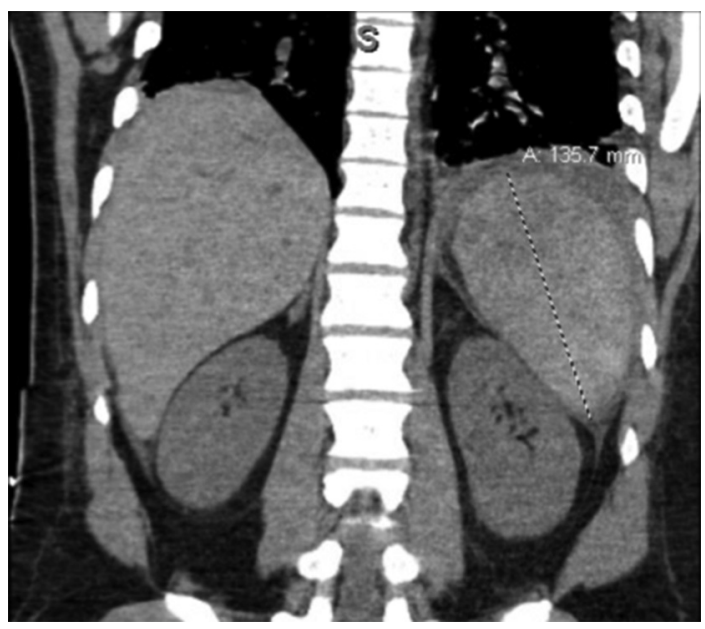

Figure 3: Immediate postprocedure computed tomography demonstrating interval development of perisplenic fluid perform a PSAE. The lower-to-mid portions of the spleen were embolized with 500-700 $\mu \mathrm{m}$ particles followed by gelfoam mixed with gentamicin $80 \mathrm{mg}$ until stasis was achieved. Final run DSA showed $70 \%-80 \%$ of the splenic parenchyma was embolized with $20 \%-30 \%$ residual arterial supply [Figure 2].

Following the procedure, the patient's remained clinically stable, and his hemoglobin continued to trend upward until it stabilized at $6 \mathrm{~g} / \mathrm{dl}$. The patient's postprocedure course was complicated by severe left upper quadrant abdominal pain which was managed with opioid medication. A CT scan showed perisplenic fluid related to the embolization [Figure 3]. Laboratory results showed increasing haptoglobin and decreasing LDH [Figure 4]. On postprocedure day 8 , the patient was given another dose of rituximab and discharged with outpatient follow-up.

In the outpatient setting, he was continued on oral steroids and given the fourth, final dose of rituximab 1 week after discharge to complete his regimen. Two months after the procedure, the patient complained of severe left upper quadrant pain again. CT of the abdomen showed

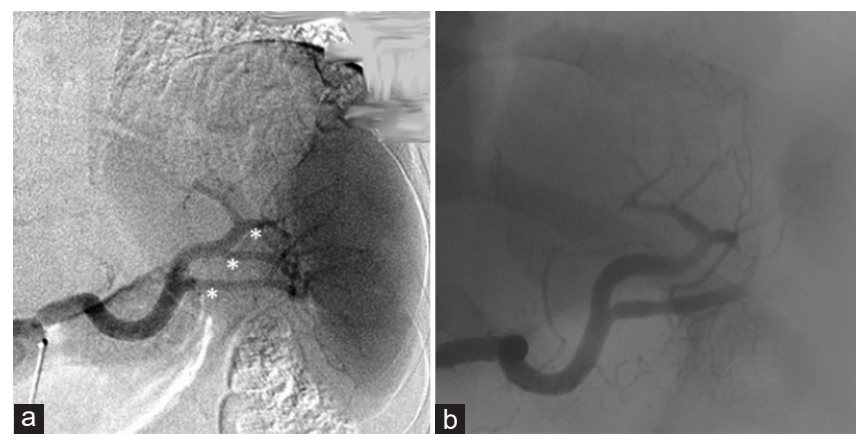

Figure 2: (a) Preembolization angiography of the splenic artery showing the three lower branches to be embolized (asterisks). (b) Postembolization angiography of the splenic artery with $20 \%-30 \%$ residual blood supply to the superior pole

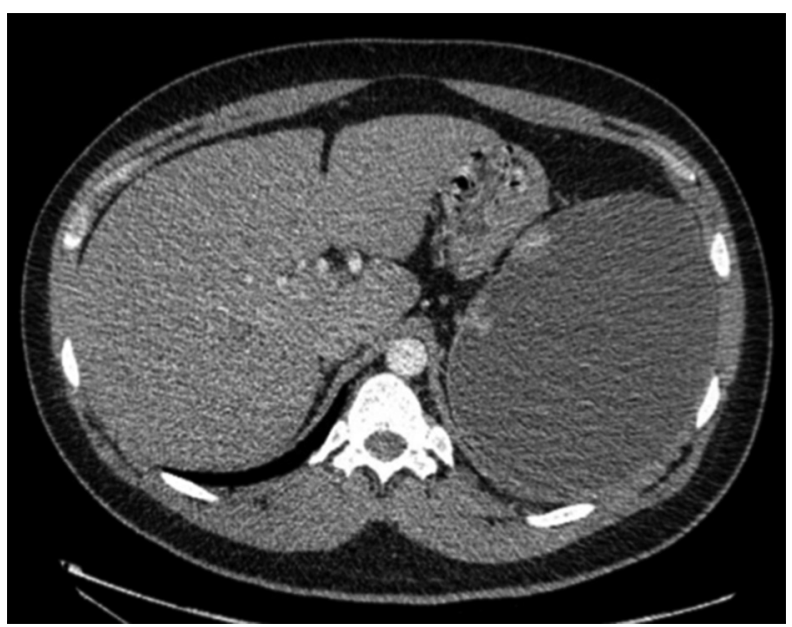

Figure 4: Computed tomography abdomen 2 months postprocedure showing the formation of a splenic pseudocyst 

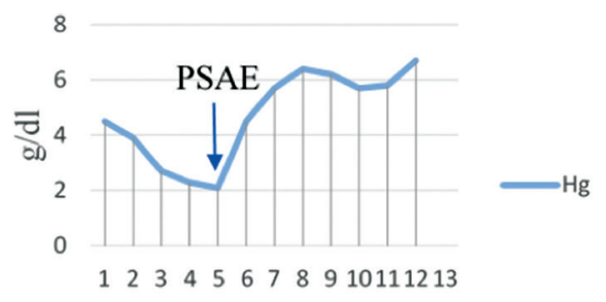

Hospital Days
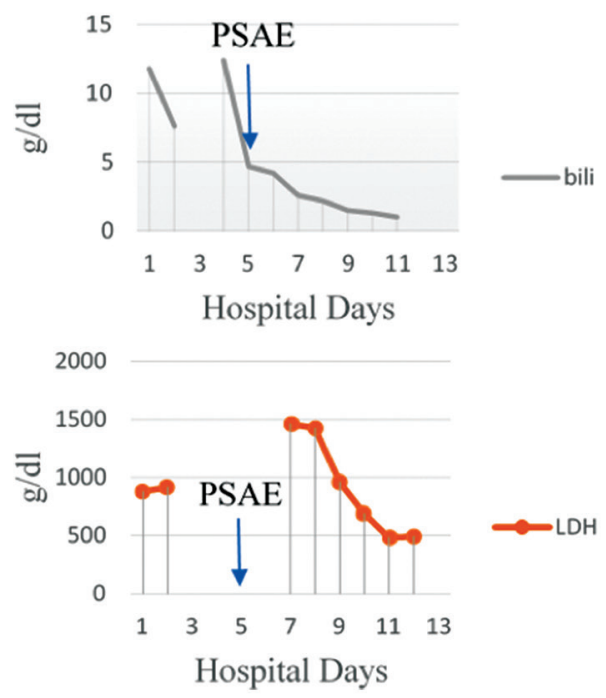

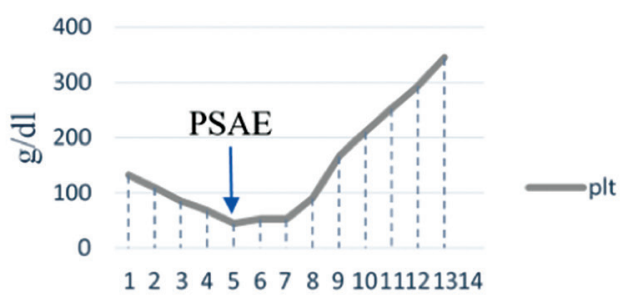

Hospital Days

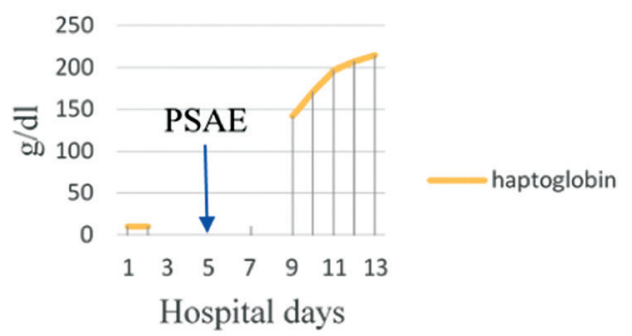

Figure 5: Inpatient change in pertinent laboratory values hemoglobin, platelets, bilirubin, haptoglobin, and lactate dehydrogenase over the patient's hospital course. Note, hospital day 4 bilirubin is likely a laboratary error

devitalized splenic parenchyma with the formation of a secondary splenic cyst [Figure 5]. There was no evidence of abscess. The patient was afebrile without leukocytosis, but because of his persistent pain, he was scheduled for an elective splenectomy approximately 3 months after the embolization procedure. There were no surgical complications. Surgical specimen pathology showed hemosiderin-laden macrophages and extensive infarction with necrosis and secondary splenic cyst formation. Six months postprocedure, the patient is doing well clinically, and his abdominal pain has resolved. His most recent $\mathrm{Hg}$ was $14 \mathrm{~g} / \mathrm{dl}$. He has not required any further transfusions.

\section{Discussion}

PSAE was used in the second half of the $20^{\text {th }}$ century as treatment for leukopenia in renal transplant recipients. Since then, it has been performed for a variety of indications including hypersplenism, blunt abdominal trauma, and immune thrombocytopenic purpura. ${ }^{[1-4]}$ The use of PSAE for AIHA, however, is limited to rare case reports. ${ }^{[4-6]}$

All three previously reported cases had rapid improvement in hemolysis post-PSAE. In two cases where PSAE was used as a definitive, sole therapy, the patients survived with no mention of complications after 4 and 8 months of follow-up, respectively. ${ }^{[4,6]}$ The intervention was performed without the intention of further surgical intervention. However, persistent pain due to the secondary splenic cyst formation made surgery necessary.

Which patients respond best to PSAE is unknown, but it is reasonable to assume that PSAE, like splenectomy, is only effective for IgG-mediated extravascular AIHA that occurs primarily in the spleen. ${ }^{[7]}$ In contrast, with conditions such as paroxysmal nocturnal hemoglobinuria and cold AIHA, which is IgM mediated, embolizing the spleen will be ineffective because the hemolysis is intravascular. ${ }^{[8,9]}$ In addition, deriving from surgical literature, patients with primary hemolytic, rather than hemolytic anemia secondary to drug use or a primary malignancy, are probably more likely to have a complete response. ${ }^{[10]}$ The patient was a good candidate because he had primary warm AIHA with obvious new-onset splenomegaly on imaging.

\section{Conclusion}

Our case shows the utility of PSAE as an acute life-saving intervention for a poor surgical candidate with idiopathic warm AIHA refractory to medical therapy.

\section{Declaration of patient consent}

The authors certify that they have obtained all appropriate patient consent forms. In the form the patient(s) has/have given his/her/their consent for his/her/their images and 
other clinical information to be reported in the journal. The patients understand that their names and initials will not be published and due efforts will be made to conceal their identity, but anonymity cannot be guaranteed.

\section{Financial support and sponsorship}

Nil.

\section{Conflicts of interest}

There are no conflicts of interest.

\section{References}

1. Spigos DG, Jonasson O, Mozes M, Capek V. Partial splenic embolization in the treatment of hypersplenism. AJR Am J Roentgenol 1979;132:777-82.

2. Madoff DC, Denys A, Wallace MJ, Murthy R, Gupta S, Pillsbury EP, et al. Splenic arterial interventions: Anatomy, indications, technical considerations, and potential complications. Radiographics 2005;25 Suppl 1:S191-211.

3. Miyazaki M, Itoh H, Kaiho T, Ohtawa S, Ambiru S, Hayashi S, et al. Partial splenic embolization for the treatment of chronic idiopathic thrombocytopenic purpura. AJR Am J Roentgenol 1994;163:123-6.
4. Guan YS, Hu Y. Clinical application of partial splenic embolization. ScientificWorldJournal 2014;2014:961345.

5. Creelan B, Thomas K, Massis K, Davis RM. Splenic arterial embolization for idiopathic warm auto-immune haemolytic anaemia. Br J Haematol 2013;161:2.

6. Durusu Tanrı̈̈ver M, Peynircioğlu B, Ergan Arsava B, Topeli İskit A. Splenic artery embolization: An alternative approach in a critically ill patient with autoimmune hemolytic anemia. Turk J Haematol 2011;28:135-8.

7. Berentsen S. How I manage cold agglutinin disease. $\mathrm{Br} \mathrm{J}$ Haematol 2011;153:309-17.

8. Molica M, Massaro F, Annechini G, Baldacci E, D’Elia GM, Rosati R, et al. Life-threatening autoimmune hemolytic anemia and idhiopatic thrombocytopenic purpura. Successful selective splenic artery embolization. Mediterr $\mathrm{J}$ Hematol Infect Dis 2016;8:e2016020.

9. Crowther M, Chan YL, Garbett IK, Lim W, Vickers MA, Crowther MA. Evidence-based focused review of the treatment of idiopathic warm immune hemolytic anemia in adults. Blood 2011;118:4036-40.

10. Akpek G, McAneny D, Weintraub L. Comparative response to splenectomy in Coombs-positive autoimmune hemolytic anemia with or without associated disease. Am J Hematol 1999;61:98-102. 